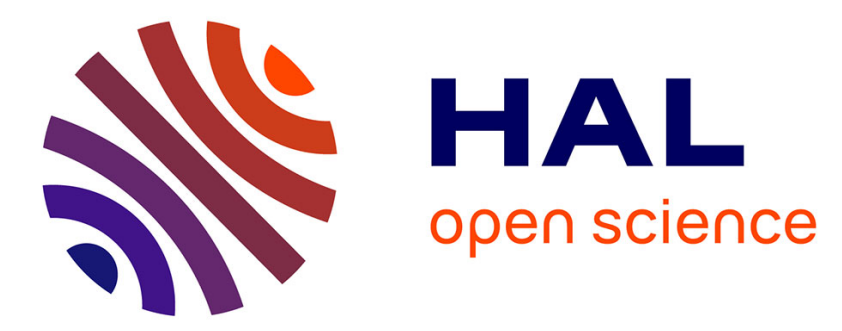

\title{
On the Cognitive Processes Underlying Contextual Interference: Contributions of Practice Schedule, Task Similarity and Amount of Practice
}

Arnaud Boutin, Yannick Blandin

\section{- To cite this version: \\ Arnaud Boutin, Yannick Blandin. On the Cognitive Processes Underlying Contextual Interference: \\ Contributions of Practice Schedule, Task Similarity and Amount of Practice. Human Movement Science, 2010, 29 (6), pp.910-920. 10.1016/j.humov.2010.07.011 . hal-00692327}

\section{HAL Id: hal-00692327 \\ https://hal.science/hal-00692327}

Submitted on 30 Apr 2012

HAL is a multi-disciplinary open access archive for the deposit and dissemination of scientific research documents, whether they are published or not. The documents may come from teaching and research institutions in France or abroad, or from public or private research centers.
L'archive ouverte pluridisciplinaire HAL, est destinée au dépôt et à la diffusion de documents scientifiques de niveau recherche, publiés ou non, émanant des établissements d'enseignement et de recherche français ou étrangers, des laboratoires publics ou privés. 


\section{Accepted Manuscript}

On the Cognitive Processes Underlying Contextual Interference: Contributions of Practice Schedule, Task Similarity and Amount of Practice

Arnaud Boutin, Yannick Blandin

PII:

S0167-9457(10)00110-7

DOI:

10.1016/j.humov.2010.07.011

Reference:

HUMOV 1272

To appear in:

\section{Human Movement Science}

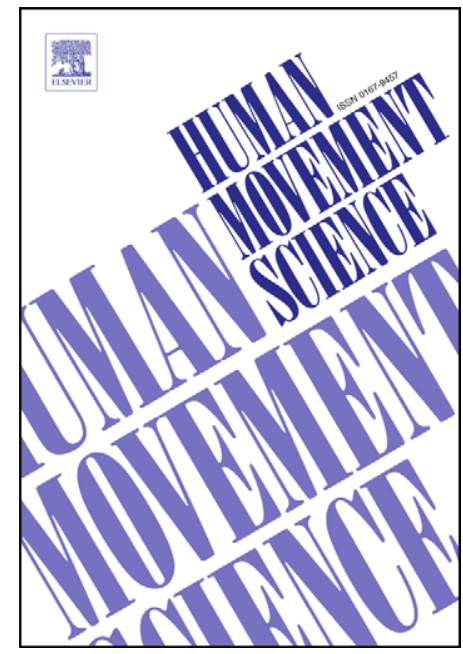

Please cite this article as: Boutin, A., Blandin, Y., On the Cognitive Processes Underlying Contextual Interference: Contributions of Practice Schedule, Task Similarity and Amount of Practice, Human Movement Science (2010), doi: 10.1016/j.humov.2010.07.011

This is a PDF file of an unedited manuscript that has been accepted for publication. As a service to our customers we are providing this early version of the manuscript. The manuscript will undergo copyediting, typesetting, and review of the resulting proof before it is published in its final form. Please note that during the production process errors may be discovered which could affect the content, and all legal disclaimers that apply to the journal pertain. 
On the Cognitive Processes Underlying Contextual Interference:

Contributions of Practice Schedule, Task Similarity and Amount of Practice

Arnaud Boutin and Yannick Blandin

Correspondence address: Yannick Blandin

Centre de Recherches sur la Cognition et l'Apprentissage

Maison des Sciences de l'Homme et de la Société

99, Avenue du Recteur Pineau

86000 Poitiers, France

Tel: + 33(0)549454699

Fax: + 33(0)5 49454647

E-mail: yannick.blandin@mshs.univ-poitiers.fr

Running Head: Cognitive Processes Underlying Contextual Interference.

Key words: Contextual interference; Motor learning; Intertask processing; Task similarity;

Amount of practice. 


\begin{abstract}
This experiment was designed to assess the combined influence of practice schedule (blocked or random), task similarity (similar or dissimilar), and amount of practice on motor learning. Participants were required to perform three movement times $(200,350,500 \mathrm{~ms})$ in a blocked or random schedule while pointing towards the target located in the front direction in the similar condition, or towards three targets (left, front, and right) in the dissimilar condition. In each condition, participants completed 99 or 297 acquisition trials before a delayed retention test similar for all participants. Results indicated a contextual interference (CI) effect due to the schedule of practice following 297 trials for similar task: blocked schedule tended to produce better performance early in practice; random schedule enhanced learning for a larger amount of practice. However, when participants experienced dissimilar task variations, no blocked-random difference was found whatever the amount of practice. This suggests that task similarity is a learning variable that modulates the CI effect. Our findings argue for the evidence that the intertask processing evoked by random schedule is not sufficient to improve learning and that there may be a ceiling effect on retention performance due to the extent of additional intertask processing.
\end{abstract}




\section{Introduction}

Over the last 30 years, considerable attention has been focused on the contextual interference $(\mathrm{CI})$ effect. Since its initial demonstration in the motor domain by Shea and Morgan (1979), and according to Battig's original work (1966) in the verbal domain, this effect is considered as a performance paradox: interference between tasks to be learned during practice may hinder immediate performance but facilitate and enhance the ensuing retention performance (see Magill \& Hall, 1990, for a review). In others words, CI refers to the finding that practice of multiple tasks or variants of the same task under a random schedule (i.e., different tasks are practiced on consecutive trials) leads to better retention performance when compared to a blocked schedule (i.e., all trials on one task are completed before the next task was introduced). Up to now, this pattern of results has been largely reproduced in the verbal and motor domains and for logical rule learning (e.g., Schneider, Healy, Ericsson, \& Bourne, 1995). It is of particular interest, however, to understand the information-processing mechanisms underlying this phenomenon (e.g., Blandin, Proteau, \& Alain, 1994; Blandin \& Proteau, 1997; Cross, Schmitt, \& Grafton, 2007; Lin, Fisher, Winstein, Wu, \& Gordon, 2008; Lin et al., 2009).

To address this issue, two principal theoretical explanations originating from the verbal skill literature have been put forward (see Lee \& Simon, 2004; Magill \& Hall, 1990, for reviews): the elaboration hypothesis (Shea \& Morgan, 1979; Shea \& Zimny, 1983, 1988) and the reconstruction hypothesis (Lee \& Magill, 1983, 1985). Based upon Battig's original work (1972, 1979), Shea and colleagues proposed that random practice forces the learner to engage in more elaborate and distinctive processing, such as intertask comparisons. Indeed, because the multiple task variations to be learned reside together in working memory, they can be compared and contrasted at any given time during acquisition. Such comparisons during practice are not possible under blocked practice because only one task is present in working 
memory. Therefore, the more practice in a random condition, the more opportunities there are to compare the different movement representations that reside in working memory with each other, and the more distinct they become from each other. Overall, intertask elaboration is considered to be critical in allowing the learner to formulate a detailed task representation that is also assumed to facilitate retention performance (e.g., Wright, 1991; Wright, Li, \& Whitacre, 1992; Young, Cohen, \& Husak, 1993).

On the other hand, the basic tenet of the reconstruction hypothesis (Lee \& Magill, 1983, 1985) postulates that the intervening trials that take place between the realization of each instance of a particular task under random practice cause participants to forget some aspects of the action plan required to perform it and, therefore, engages participants in a deeper reconstructive processing to generate an action plan before executing the forthcoming movement (see Cross et al., 2007). In contrast, during blocked practice, little reconstructive activity is necessary because the requisite information already resides in working memory. Thus, the reconstruction processes assumed to be responsible for the learning benefits may be bypassed or at least minimized in the case of blocked practice. Both the elaboration and reconstruction hypotheses assume that participants who experienced random practice during acquisition engage in additional cognitive activity (i.e., intertask elaboration or reconstructive processing) beyond that employed by their blocked practice counterparts.

Up to now, the schedule of practice (i.e., blocked versus random practice) was mainly used as a source of interference, especially in the motor domain, and little attention has been devoted to other factors supposed to produce intertask interference. According to Battig (1972, 1979), CI can also be created by increasing the degree of task similarity and the main purpose of the present study was to further examine the extent to which intertask elaboration and reconstruction are beneficial for learning highly similar or dissimilar task variations practiced under blocked or random contexts. In others words, we have tested the combined 
influence of practice schedule and task similarity on learning in order to emphasize the component process underlying the CI phenomenon.

Originally presented by Battig $(1972,1979)$ in the verbal skill literature, the notion of "task similarity" was used in relation to the semantic similarity of words that would be learned on a word list. Findings revealed that words on a list that are quite similar create more interference during practice than dissimilar words. However, although task similarity has been found to increase the CI effect in the verbal skill literature, there is modest evidence so far about the potential learning benefits of task similarity in the motor domain. Wood and Ging (1991) have done work based on this premise, following earlier work by Shea and Zimny (1988). They defined task similarity as a function of the spatial characteristics of three movement patterns to be reproduced: different sizes of letter " $\mathrm{N}$ " were considered as similar; varied shapes in movement pattern were considered as dissimilar. Learning benefits were found for random compared to blocked practice in the dissimilar condition, whereas no practice schedule differences were observed in the similar condition. Furthermore, contrary to Battig (1972, 1979), offering individuals the chance to perform highly similar tasks during a period of random practice does not improve retention performance beyond that demonstrated by individuals experiencing dissimilar tasks in a random format.

Nevertheless, one could assume that this apparent discrepancy might be overcome by arguing about the term "similarity". In fact, this prediction is contingent upon how one defines task similarity related to motor skills. In fact, while Battig discussed "task similarity" in terms of the semantic characteristics of the items to be learned in the verbal skill literature, this latter notion should be differently interpreted when motor tasks are considered, that is, when considering "task similarity" in light of the context in which it is used (see also Shea \& Zimny, 1988). However, such a definition of "task similarity" for a wide variety of motor tasks appears to be a difficult challenge, if not impossible, for many theoretical reasons. The 
question is whether this notion developed primarily through the study of verbal tasks, could be generalized to the learning of motor tasks. Experiments to address this issue need to be set up, first to provide experimental evidence in favor of a particular theory, and second to be free of other inappropriate explanations. Therefore, it seems reasonable, even though a couple of experiments (Shea \& Zimny, 1988; Wood \& Ging, 1991) varied task requirements based on spatial configurations of tasks classified as similar or dissimilar, to consider an alternative definition of task similarity. In the present experiment, task similarity was based on the parametric conception of movement programming (Rosenbaum, 1980,1983). We have used a keypress task with specific parameter constraints, such as movement time and movement direction requirements, rather than task variations that merely rely on spatial configurations (Shea \& Zimny, 1998; Wood \& Ging, 1991).

According to Rosenbaum (1980, 1983; see also Lépine, Glencross, \& Requin, 1989; Anson, Hyland, Kötter, \& Wickens, 2000), motor programming is a parametric process in that each movement dimension is independently specified, such as arm (e.g., left or right), direction (e g., toward or away from the frontal plane of the body) and extent (e.g., long or short). In the present experiment, participants assigned to the similar parameter condition pointed towards a unique target located in the front direction while participants in the dissimilar parameter condition pointed towards three possible targets (left, right, or front). To sum up, if the proposal of Battig $(1972,1979)$ is correct and applies to motor tasks, several predictions could be made. According to Battig, interference should increase as tasks become more similar or when practiced in a random context. Specifically, either manipulation should increase the interference level created during practice and enhance ensuing retention performance. Furthermore, when controlled within the same experiment, task similarity and schedule of practice should interact, resulting in larger blocked-random differences in retention when participants experienced highly similar compared to dissimilar task variations. 
Briefly, if the intertask elaboration needed under both random schedule and similar task variations (i.e., higher elaborate and distinctive processing) are combined, the random-similar condition should produce higher CI during acquisition and favor long term learning. Conversely, because the intratask processing is the only one that takes place under blocked schedule, no or few differences should be expected for this schedule as a function of task similarities.

Lastly, another question asked was whether the amount of practice would also interact with the CI effect. Indeed, the amount of practice provided during acquisition has been reported as a possible determinant for the CI effect to occur (e.g., Proteau, Blandin, Alain, \& Dorion, 1994; Shea, Kohl, \& Indermill, 1990). Shea et al. (1990) investigated the relationship between $\mathrm{CI}$ and the amount of practice completed on a discrete movement task $(50,200$, or 400 trials). They stated that the benefits of random practice, relative to blocked practice, surface for larger amounts of practice because of increased intertask processing. In line with Shea et al. (1990) experiment, in the present study we also used a discrete movement task which is supposed to minimize on-line corrections (see Shea et al.,1990) and to promote larger effect sizes (see Lee \& Simon, 2004, for a review). Thus, we would predict higher retention performance with increased random practice while experiencing highly similar tasks because of increased variable processing strategies adopted by participants when faced with increased intertask elaboration.

\section{Method}

\section{Participants}

Participants were 108 right-handed volunteer students (mean age $=22.5$ years, $S D=3.8$ years) who had no prior experience with the experimental task and were unaware of the specific purposes of the study. Upon arrival at the testing room, each participant completed an 
informed consent form and received written and verbal instructions regarding the goals of the task. Participants were individually tested in a silent and dimly lit room. They were asked to be seated on a chair in front of the computer monitor and to adjust the position of the response panel to be comfortable.

\section{Apparatus and Task}

The apparatus consisted of a response panel and a computer/monitor, positioned on a table. The response panel (Fig. 1) consisted of a wooden board $(50 \times 50 \mathrm{~cm})$ with four microswitches $(2.5 \mathrm{~cm}$ in diameter) placed $20 \mathrm{~cm}$ apart from each other. Each microswitch was interfaced with a computer so that the timing of the microswitch presses could be measured in milliseconds and recorded for later analysis. All aspects of the experiment were programmed with the E-Prime ${ }^{\circledR}$ version 1.1 software from Psychology Software Tools (@ 2002 Psychology Software Tools, Inc., Pittsburgh, PA).

From the starting microswitch (designated as "A" in Fig. 1) participants had to depress the requested microswitch (designated as "B", "C" or "D" in Fig. 1) with their right hand while meeting one of three absolute timing goals (ATG). ATG was defined as the amount of time elapsed from the release of the "A" microswitch to the depressing of the requested microswitch. The ATGs required for all participants were 200, 350, and $500 \mathrm{~ms}$.

Insert Fig. 1 about here

Prior to each trial, the message "PRESS THE START BUTTON" was displayed in the center of the screen, requiring participants to depress the starting microswitch with their right hand. When the start position was achieved, this message was replaced with a symbol composed of three arrows that represented the three possible movement directions ("B", "C", 
or "D"). This symbol was presented in the center of the screen for a variable foreperiod of 1 , 2, or $3 \mathrm{~s}$, after which the imperative signal (one arrow turned in bold type with the imposed ATG) was displayed in the same location as the symbol (see Fig. 1). Participants were informed that they should initiate their response as quickly and accurately as possible. They were allowed up to $4 \mathrm{~s}$ to perform the required response. Otherwise, an error message appeared in the middle of the screen and the trial was repeated. At the end of each trial, Knowledge of Results (KR) was displayed for 5 s. KR included the ATG above the participant's Actual Movement Time (AMT), both in milliseconds. Note that erroneous trials like missing the ending microswitch or depressing the wrong one were reintroduced at the end of a trial block; only error-free responses were included in the analyses.

\section{Experimental groups and procedures}

Prior to entering the testing room, participants were randomly assigned to one of eight acquisition conditions in a $2 \times 2 \times 2$ (Practice schedule $\times$ Task similarity $\times$ Amount of practice) design: four groups $(N=15)$ performed 99 acquisition trials while the other four groups $(N=12)$ performed 297 acquisition trials during acquisition. This resulted in eight independent groups which differed in terms of practice schedule (blocked vs. random), task similarity (similar ys. dissimilar), and amount of practice (99 vs. 297 trials).

This 2-day experiment consisted of two phases: acquisition and retention. During the acquisition phase, participants performed a total of 99 or 297 trials on the three ATGs (respectively 33 or 99 trials for each ATG). Participants assigned to the similar parameter condition performed the three ATGs $(200,350$ and $500 \mathrm{~ms})$ while pointing towards the target located in the front direction. Participants in the dissimilar parameter condition performed the three ATGs towards the three possible targets. However, for the dissimilar parameter condition, the $350 \mathrm{~ms}$ ATG was always associated with the front target. The 200 and $500 \mathrm{~ms}$ 
ATG were either associated with the left or the right target (counterbalanced across participants of the dissimilar condition). During acquisition, blocks of 9 trials were administered. Participants assigned to random practice experienced 3 trials for each of the three task variations within each block of 9 trials, with the constraint that the same response was not presented on more than two consecutive trials. Participants in the blocked condition completed 33 or 99 trials on one task variation before another task variation was introduced. The order of task presentation in the blocked condition was counterbalanced across participants.

Approximately 24 hours after the completion of the acquisition phase, participants were administered a retention test, which consisted of 18 no-KR trials on the only task variation common to all participants in acquisition: the front target associated with the $350 \mathrm{~ms}$ ATG. With the exception that KR was not provided to participants during retention, procedures remained the same as those used for acquisition. Participants were again encouraged to execute the response as quickly and accurately as possible without making error.

\section{Results}

The AMT (in ms) was recorded for each trial during the acquisition and retention. The dependent variables of interest were the Absolute Constant Error (ACE) and the Variable Error (VE) computed for blocks of 9 trials for acquisition (3 trials for each ATG) and for 18 trials for retention test. The ACE provides an estimate of the accuracy with which the outcome movement was scaled in time. ACE was computed by taking the absolute difference between the ATG and the AMT. VE is a measure of response variability that is computed as the standard deviation of the signed errors. No analysis for error was done (2-3\% maximum across participants). 


\section{Acquisition phase}

Low amount of practice (99 trials). Data were analyzed with a Practice schedule $($ Blocked, Random $) \times$ Similarity condition $($ Similar, Dissimilar $) \times$ ATG $(200,350,500) \times$ Block (1-11) analysis of variance (ANOVA) with repeated measures on the last two factors. The analysis of ACE indicated significant main effects of practice schedule, $F(1,56)=13.72$, $p<.05, \eta_{\mathrm{p}}^{2}=0.19 ;$ similarity condition, $F(1,56)=4.03, p<.05, \eta_{\mathrm{p}}^{2}=0.06 ;$ ATG, $F(2,112)=$ 174.81, $p<.05, \eta_{p}^{2}=0.75$; and block, $F(10,560)=30.68, p<.05, \eta_{p}^{2}=0.35$ (see Fig. 2 A). The practice schedule main effect revealed that participants experiencing blocked practice exhibited lower mean ACE (44.80 ms) than their random practice counterparts $(52.20 \mathrm{~ms})$. Analysis of similarity condition indicated that smaller errors were made in the similar parameter condition $(46.49 \mathrm{~ms})$ compared to the dissimilar parameter condition $(50.50 \mathrm{~ms})$. The ATG main effect revealed that performances were more accurate for the $200 \mathrm{~ms}$ ATG (31.23 ms) than for the $350 \mathrm{~ms}$ ATG $(46.87 \mathrm{~ms})$ and the $500 \mathrm{~ms}$ ATG $(67.40 \mathrm{~ms})$. The ACE for the latter ATGs also differed significantly $(p<.05)$. Finally, Newmann-Keuls post-hoc comparisons indicated that the mean ACE decreased from Block 1 (73.68 ms) to Block 3 (49.09 ms).

The analysis of VE revealed significant main effects of practice schedule, $F(1,56)=$ $14.09, p<.05, \eta_{\mathrm{p}}^{2}=0.20 ;$ ATG, $F(2,112)=191.79, p<.05, \eta^{2}{ }_{\mathrm{p}}=0.77 ;$ and block, $F(10,560)$ $=13.40, p<.05, \eta_{\mathrm{p}}^{2}=0.19$ (see Fig. 2B). The main effect of practice schedule was a result of lower VE for groups trained under blocked practice $(34.21 \mathrm{~ms})$ than for their random practice counterparts (39.53 ms). For the ATG main effect, subsequent post-hoc analysis revealed lower mean VE for the $200 \mathrm{~ms}$ ATG (22.94 ms) compared to VE for the $350 \mathrm{~ms}$ ATG (38.60 $\mathrm{ms}$ ) and the $500 \mathrm{~ms}$ ATG (49.06 ms). The VE for the latter ATGs also differed significantly $(p<.05)$. Finally, the block main effect indicated that the VE was higher for Block 1 and 2 
(50.14 and $47.77 \mathrm{~ms}$, respectively) than for all subsequent blocks. The VE for Block 1 and Block 2 also differed significantly $(p<.05)$.

High amount of practice (297 trials). Data were analyzed with a Practice schedule $($ Blocked, Random $) \times$ Similarity condition $($ Similar, Dissimilar $) \times$ ATG $(200,350,500) \times$ Block (1-33) analysis of variance (ANOVA) with repeated measures on the last two factors. The analysis of ACE indicated significant main effects of practice schedule, $F(1,44)=27.16$, $p<.05, \eta_{\mathrm{p}}^{2}=0.38 ;$ ATG, $F(2,88)=144.01, p<.05, \eta_{\mathrm{p}}^{2}=0.76$; and block, $F(32,1408)=$ 16.16, $p<.05, \eta_{\mathrm{p}}^{2}=0.26$ (see Fig. 2C). Participants trained in a blocked schedule exhibited lower mean ACE (36.35 ms) compared to their random practice counterparts $(47.74 \mathrm{~ms})$. Again, the ATG main effect revealed that performances were more accurate for the $200 \mathrm{~ms}$ ATG $(27.49 \mathrm{~ms})$ than for the $350 \mathrm{~ms}$ ATG $(40.65 \mathrm{~ms})$ and the $500 \mathrm{~ms}$ ATG $(58.01 \mathrm{~ms})$. The ACE for the latter ATGs also differed significantly $(p<.05)$. Simple main effect analysis across blocks indicated that the mean ACE decreased from Block 1 (72.61 ms) to Block 4 (45.50 ms).

The analysis of VE revealed significant main effects of practice schedule, $F(1,44)=$ 25.93, $p<.05, \eta_{\mathrm{p}}{ }^{2}=0.37$; ATG, $F(2,88)=219.76, p<.05, \eta^{2}{ }_{\mathrm{p}}=0.83$; and block, $F(32,1408)$ $=8.61, p<.05, \eta_{\mathrm{p}}^{2}=0.16$ (see Fig. 2D). Across acquisition, mean VE were smaller for the blocked practice groups $(28.86 \mathrm{~ms})$ than the random practice groups $(36.28 \mathrm{~ms})$. The ATG main effect revealed lower mean VE for the 200 ms ATG (19.21 ms) compared to the mean VE for the $350 \mathrm{~ms}$ ATG $(33.47 \mathrm{~ms})$ and the $500 \mathrm{~ms}$ ATG $(45.04 \mathrm{~ms})$. The VE for the latter ATGs also differed significantly $(p<.05)$. Mean VE was significantly greater in Block 1 and 2 (52.16 and $41.24 \mathrm{~ms}$, respectively) than for all subsequent blocks. The VE for Block 1 and Block 2 also differed significantly $(p<.05)$. 


\section{Retention phase}

To assess motor learning, participants performed a delayed retention test that consisted of 18 no-KR trials on the task variation common to all participants in acquisition (i.e., the front target associated with the $350 \mathrm{~ms}$ ATG). Data were analyzed with a Practice schedule (Blocked, Random) $\times$ Similarity condition $($ Similar, Dissimilar $) \times$ Amount of practice $(99$, 297 trials) ANOVA. The analysis of mean ACE detected significant Practice schedule $\times$ Amount of practice, $F(1,100)=8.81, p<.05, \eta^{2}{ }_{p}=0.08$; and Practice schedule $\times$ Similarity condition $\times$ Amount of practice interactions, $F(1,100)=5.75, p<.05, \eta^{2}{ }_{p}=0.05$ (see Fig. 3A). The Practice schedule $\times$ Similarity condition $\times$ Amount of practice interaction revealed blocked-random differences in the similar parameter condition following a high amount of practice (76.01 and $38.49 \mathrm{~ms}$, respectively), but not after a low amount of practice (respectively 33.59 and $56.38 \mathrm{~ms}, p=.18$ ). In contrast, and irrespective of the amount of practice, the analysis failed to detect blocked-random differences in the dissimilar parameter condition (56.01 ms and $59.41 \mathrm{~ms}$, respectively).

The analysis of VE failed to indicate significant main effects or interaction (Fig. 3B).

Insert Fig. 3 about here

\section{Discussion}

Our primary purpose in this study was to use both practice schedule and task similarity as potential sources of interference in order (1) to examine whether contextual interference (CI) could be created by increasing the degree of task similarity, (2) to assess the combined influence of practice schedule and task similarity on motor learning, and (3) to investigate the relationship between $\mathrm{CI}$ and amount of practice. This experiment was further designed to 
address and extend the current interpretations (i.e., elaboration and reconstruction hypotheses) and the component process underlying the so-called CI effect (Shea \& Morgan, 1979; Shea \& Zimny, 1983; Lee \& Magill, 1983, 1985). Each of these issues will be examined in the following sections.

\section{Additional intertask elaboration}

According to the verbal skill literature (Battig, 1972, 1979), interference should increase as tasks become more similar or by scheduling practice in an unsystematic order because of increased intertask elaboration. Conversely, our findings for the acquisition phase revealed that experiencing highly similar tasks under random context did not result in poorer acquisition performance. Although this result is in line with previous findings reported by Wood and Ging (1991), it is contrary to Battig's proposal. Specifically, participants did not produce the heightened state of cognitive activity when faced with increased intertask elaboration; at least as indicated by performance accuracy. On the other hand, the results reproduced the classical influence of practice schedule as a source of interference during acquisition: interference created by random practice negatively affected performance, resulting in slower acquisition rates for random than for blocked practice (Magill \& Hall, 1990, for a review).

Of particular interest, however, was the finding that the degree of similarity between tasks impacts learning as evaluated by retention test. In fact, data revealed blocked-random differences only in the similar parameter condition: while the blocked practice group tends to produce better performance early in practice (i.e., 99 acquisition trials), learning benefits of random schedule surface after 297 acquisition trials. These data are consistent with Shea et al. (1990) results and indicated that the benefits of random schedule, relative to blocked schedule, may not surface and may even be detrimental until sufficient amounts of acquisition 
trials are completed because of an increased possibility for between-task comparisons (i.e., elaborative processing). This suggests there might be an upper limit on the extent of intertask elaboration that should be induced for a given amount of practice to promote learning (see also Wright, Li, \& Whitacre, 1992). In contrast, the same conclusion cannot be drawn from the data that emanated from participants assigned to the dissimilar parameter condition: no blocked-random difference was found during retention for participants who experienced dissimilar task variations. Obviously, this suggests that task similarity seems to be a learning variable that is likely to modulate the CI effect.

Moreover, consistent with previous findings of Lin et al. (2008), our study further supports the beneficial influence of engaging intertask elaboration. Namely, experiencing highly similar tasks under random context promotes learning after sufficient practice because of increased intertask processing; in the case of task similarity, intertask processing refers to additional elaborative and distinctive processes needed for between-tasks discrimination. Heretofore, the retention findings lend support for the intertask elaboration as a relevant component process underlying the CI effect. However, contrary to Battig's findings (1972, 1979) in verbal skill learning, our results also revealed that increased similarity between motor tasks did not facilitate retention performance if not combined with a random practice schedule. Therefore, these data are difficult to reconcile within the present delineation of the elaboration hypothesis, which in turn, appears to mainly refer as well as the reconstruction hypothesis to the effect of the schedule of practice on motor learning.

\section{Refining reconstruction processing}

The present experiment was designed to assess intertask processing (elaborative and reconstructive processes) that is central to the explanation of the CI phenomenon in motor learning. However, somewhat surprisingly, an unexpected result was the lack of blocked- 
random difference in the dissimilar parameter condition, regardless of the amount of practice. This suggests that the dissimilar parameter condition requires additional intertask reconstruction that could override the blocked-random difference in retention. Because the dissimilar parameter condition implied additional reconstructive processes (i.e., reconstruction of the movement direction) relative to the similar parameter condition, our findings argue for the evidence that the reconstructive processes evoked by random but not blocked schedule are in itself not sufficient to promote retention performance (see also Shea \& Wright, 1991).

This is in line with recent findings of Lin et al. (2008) who did not fully support the reconstruction hypothesis by showing that perturbation produced by Transcranial Magnetic Stimulation (TMS) pulses during blocked practice did not promote motor learning. Of particular importance, however, is the finding that the disruption of intertrial processes during training deteriorated the learning benefits of random schedule which support the elaboration hypothesis. Overall, the findings presented herein provided important theoretical relevance about the elaboration and reconstruction hypotheses as combining accounts of the CI effect, and that there may be a ceiling effect on retention performance due to the extent of additional intertask processing. This alternative explanation will be addressed in the following section.

Beyond the elaboration and reconstruction hypotheses: An alternative explanation

As previously stated, one might accept that, in the early practice stages, additional intertask processes induced by random schedule when participants experienced highly similar tasks (i.e., additional intertask elaboration) or dissimilar tasks (i.e., additional intertask reconstruction) may have exceeded the cognitive capacity of the learner, nullifying the potential advantage of intertask interference and thus cancelling out the learning benefits usually found for random over blocked practice on delayed retention tests (see also Wulf \& Shea, 2002, for a review). Thus, what appears to be a more appropriate connection with 
Battig's views is the relationship of task difficulty and CI effect. In fact, Battig (1979) noted that the degree of CI effect could be a function of the difficulty of the task, suggesting that higher levels of task difficulty lead to greater amount of CI which, in turn, favours learning. However, on the basis of findings from previous studies that controlled task difficulty (e.g., Albaret \& Thon, 1998; Jarus \& Gutman, 2001; see also Wulf \& Shea, 2002; Guadagnoli \& Lee, 2004, for reviews), it has been suggested that experiencing complex tasks may exceed the memory capacity of the learner, preventing or at least limiting learning benefits of intertask processing induced by a random practice schedule. Further, Wulf and Shea (2002) also stated that the intratask processing inherent to complex tasks may be sufficient for effective learning under blocked schedule, at least in the early stages of practice. This statement fits well with the "challenge point" hypothesis (Guadagnoli \& Lee, 2004) which suggests that there is a desirable level of interference, for a given amount of practice, that leads to the optimal learning outcome.

The aforementioned studies have firmly provided evidence that some of the theoretical concepts developed from research on simple skills are not generalisable to complex skills. For example, the effects of practice schedule on learning would be dependent on the complexity of the tasks to be learned and/or the additional information-processing demands engaged by learners. Referring to Wulf and Shea (2002) for keypress tasks, it was suggested that task complexity tends to increase as the number of degrees of freedom increases. Namely, in agreement with their statement, one could consider the dissimilar parameter condition more complex (i.e., higher degrees of freedom induced by movement directions) than the similar parameter condition (i.e., only one movement direction) in our experiment. Thus, using the "challenge point framework" (Guadagnoli \& Lee, 2004) as a theoretical backdrop, experiencing a random practice schedule in the dissimilar parameter condition is supposed to have created too much interference so that the information-processing system became 
overwhelmed and both performance and learning were degraded. It is conceivable that the additional intertask processes required during random practice in the dissimilar parameter condition could have been detrimental for subsequent learning because the heightened state of cognitive processes engaged during training might have exceeded the limited amount of processing capacity of the learner. This perspective is also consistent with the notion that tasks judged less complex (i.e., similar parameter condition) should benefit from conditions that increase processing demands and challenge the learner (e.g., Lee, Swinnen, \& Serrien, 1994; Wulf \& Shea, 2002), while conversely tasks judged more complex should benefit from conditions that reduce the processing demands to more manageable levels for the learner.

\section{Summary}

On a more general note, data emanating from this experiment do not support the generalisability of Battig's proposal $(1972,1979)$ from verbal to motor domain, that is, the expected potential learning benefits of experiencing highly similar tasks. This study has combined both schedule of practice and task similarity as potential source of interference in order to probe the cognitive underpinnings of the CI effect, and more specifically to assess the elaboration (Shea \& Morgan, 1979; Shea \& Zimny, 1983, 1988) and reconstruction (Lee \& Magill, 1983, 1985) hypotheses. Our data lend support for the intertask elaboration as a relevant component process underlying $\mathrm{CI}$, while in contrast the intertask reconstruction is assumed in itself not sufficient to promote retention performance. From a theoretical perspective, presuming that the schedule of practice and CI effect relationship is meaningful, a major unanswered question yet, is whether the relationship between practice schedule and task similarity on the $\mathrm{CI}$ effect arise from specific processes evoked by intertask processing that account for the learning differences among blocked and random schedule. 


\section{References}

Albaret, J.-M., \& Thon, B. (1998). Differential effects of task complexity on contextual interference in a drawing task. Acta Psychologica, 100, 9-24.

Anson, J. G., Hyland, B. I., Kötter, R., \& Wickens, J. R. (2000). Parameter precuing and motor preparation. Motor Control, 4, 221-231.

Battig, W. F. (1966). Facilitation and interference. In E. A. Bilodeau (Ed.), Acquisition of skill (pp. 215-244). New York: Academic Press.

Battig, W. F. (1972). Intratask interference as a source of facilitation in transfer and retention. In R. F. Thompson \& J. F. Voss (Eds.), Topics in learning and performance (pp. 131159). New York: Academic Press.

Battig, W. F. (1979). The flexibility of human memory. In L. S. Cermak and F. I. M. Craik (Eds.), Levels of processing in human memory (pp. 23-44). Hillsdale, N. J.: Lawrence Erlbaum Associates, Inc.

Blandin, Y., Proteau, L., \& Alain, C. (1994). On the cognitive processes underlying contextual interference and observational learning. Journal of Motor Behavior, 26, 18-26.

Blandin, Y., \& Proteau, L. (1997). On the cognitive processes involved in the contextual interference effect. Journal of Human Movement Studies, 32, 211-233.

Cross, E. S., Schmitt, P. J., \& Grafton, S. T. (2007). Neural substrates of contextual interference during motor learning support a model of active preparation. Journal of Cognitive Neuroscience, 19, 1854-1871.

Guadagnoli, M. A., \& Lee, T. D., (2004). Challenge point: A framework for conceptualizing the effects of various practice conditions in motor learning. Journal of Motor Behavior, $36,212-224$. 
Jarus, T., \& Gutman, T. (2001). Effects of cognitive processes and task complexity on acquisition, retention, and transfer of motor skills. Canadian Journal of Occupational Therapy, 68, 280-289.

Lee, T. D., \& Magill, R. A. (1983). The locus of contextual interference in motor-skill acquisition. Journal of Experimental Psychology: Learning, Memory, and Cognition, 9, 730-746.

Lee, T. D., \& Magill, R. A. (1985). Can forgetting facilitate skill acquisition? In D. Goodman, R. B. Wilberg, \& I. M. Franks (Eds.), Differing perspectives in motor learning, memory, and control (pp. 3-22). Amsterdam: North-Holland.

Lee, T. D., \& Simon, D. A. (2004). Contextual interference. In A. M. Williams \& N. J. Hodges (Eds.), Skill acquisition in sport: Research, theory and practice (pp. 29-44). London: Routledge.

Lee, T. D., Swinnen, S. P., \& Serrien, D. J. (1994). Cognitive effort and motor learning. Quest, 46, 328-344.

Lin, C. H., Fisher, B. E., Winstein, C. J., Wu, A. D., \& Gordon, J. (2008). Contextual interference effect: Elaborative processing or forgetting-reconstruction? A post hoc analysis of transcranial magnetic stimulation-induced effects on motor learning. Journal of Motor Behavior, 40, 578-586.

Lin, C. H., Fisher, B. E., Wu, A. D., Ko, Y. A., Lee, L. Y., \& Winstein, C. J. (2009). Neural correlate of the contextual interference effect in motor learning: A kinematic analysis. Journal of Motor Behavior, 41, 232-242.

Lépine, D., Glencross, D., \& Requin, J. (1989). Some experimental evidence for and against a parametric conception of movement programming. Journal of Experimental Psychology: Human Perception and Performance, 15, 347-362.

Magill, R. A., \& Hall, K. G. (1990). A review of the contextual interference effect in motor skill acquisition. Human Movement Science, 9, 241-289.

Proteau, L., Blandin, Y., Alain, C., \& Dorion, A. (1994). The effects of the amount and variability of practice on the learning of a multi-segmented motor task. Acta Psychologica, 85, 61-74.

Rosenbaum, D. A. (1980). Human movement initiation: Specification of arm, direction, and extent. Journal of Experimental Psychology: General, 109, 444-474.

Rosenbaum, D. A. (1983). The movement precuing technique: Assumptions, applications, and extensions. In R. A. Magill (Ed.), Memory and control of action (pp. 231-274). Amsterdam: North-Holland. 
Schneider, V. I., Healy, A. F., Ericsson, K. A., \& Bourne, L. E. (1995). The effects of contextual interference on the acquisition and retention of logical rules. In A. F. Healy \& L. E. Bourne (Eds.), Learning and memory of knowledge and skills: Durability and specificity. (pp. 95-131). Thousand Oaks, CA: Sage.

Shea, C. H., Kohl, R., \& Indermill, C. (1990). Contextual interference: Contributions of practice. Acta Psychologica, 73, 145-157.

Shea, J. B., \& Morgan, R. L. (1979). Contextual interference effects on the acquisition, retention, and transfer of a motor skill. Journal of Experimental Psychology: Human Learning and Memory, 5, 179-187.

Shea, J. B., \& Wright, D. L. (1991). When forgetting benefits motor retention. Research Quarterly for Exercise and Sport, 62, 293-301.

Shea, J. B., \& Zimny, S. T. (1983). Context effects in memory and learning movement information. In R. A. Magill (Ed.), Memory and control of action (pp. 345-366). Amsterdam: North-Holland.

Shea, J. B., \& Zimny, S. T. (1988). Knowledge incorporation in motor representation. In O. G. Meijer \& K. Roth (Eds.), Complex movement behaviour: The motor-action controversy (pp. 289-314). Amsterdam: North-Holland.

Wood, C. A., \& Ging, C. A. (1991). The role of interference and task similarity on the acquisition, retention, and transfer of simple motor skills. Research Quarterly for Exercise and Sport, 62, 18-26.

Wright, D. L. (1991). The role of intertask and intratask processing in acquisition and retention of motor skills. Journal of Motor Behavior, 23, 139-145.

Wright, D. L., Li, Y. H., \& Whitacre, C. (1992). The contribution of elaborative processing to the contextual interference effect. Research Quarterly for Exercise and Sport, 63, 30-37.

Wulf, G., \& Shea, C. H. (2002). Principles derived from the study of simple skills do not generalize to complex skill learning. Psychonomic Bulletin \& Review, 9, 185-211.

Young, D. E., Cohen, M. J., \& Husak, W. S. (1993). Contextual interference and motor skill acquisition: On the processes that influence retention. Human Movement Science, 12, 577-600. 


\section{Authors' notes}

This work was a part of the Ph.D program of Arnaud Boutin and was presented at the conference of the North American Society for the Psychology of Sport and Physical Activity, Austin, 2009. 


\section{Figure Captions}

Fig. 1. Illustration of the experimental setup from the perspective of the participant. The microswitch "A" is considered the start position. Microswitches "B", "C" and "D" indicate the possible movement directions required in the similar (movements from "A" to " $\mathrm{C}$ ") and dissimilar (movements from "A" to "B", "C" or "D") parameter condition. Overview of the temporal sequence of events while assigned to the similar or dissimilar parameter condition. Example is for two consecutive acquisition trials performed under a random schedule.

Fig. 2. Mean absolute constant errors (A) and variable errors (B) following 99 acquisition trials and 297 trials (C and D, respectively). Error bars represent standard errors.

Fig. 3. Mean absolute constant errors (A) and variable errors (B) for the retention test as a function of the number of acquisition trials for all groups. Error bars represent standard errors. 


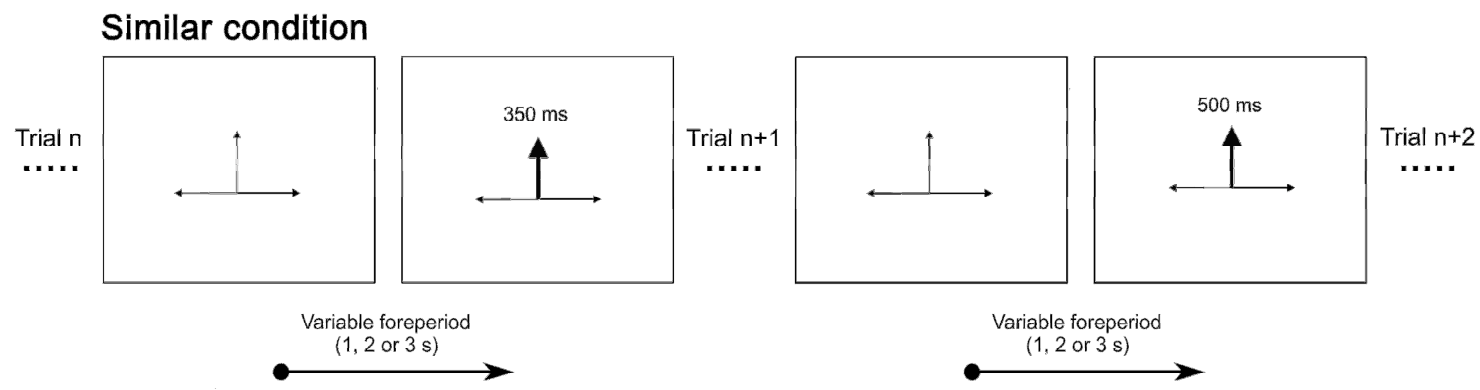

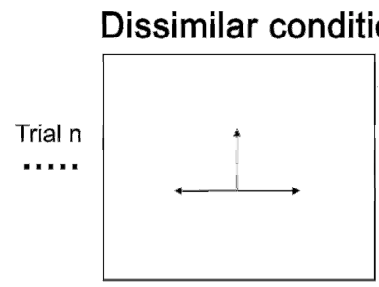

Fixation symbol
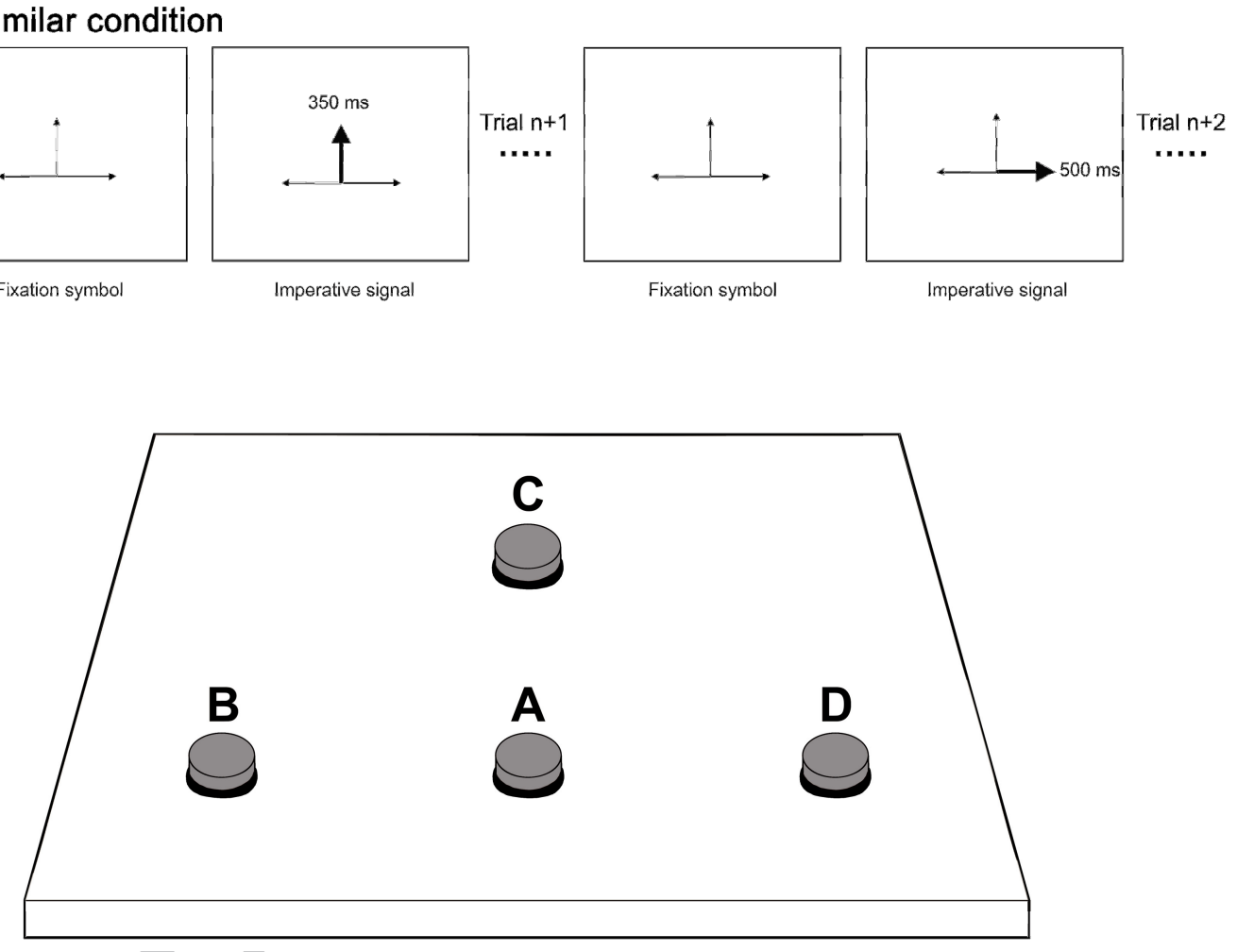

Figure 1 


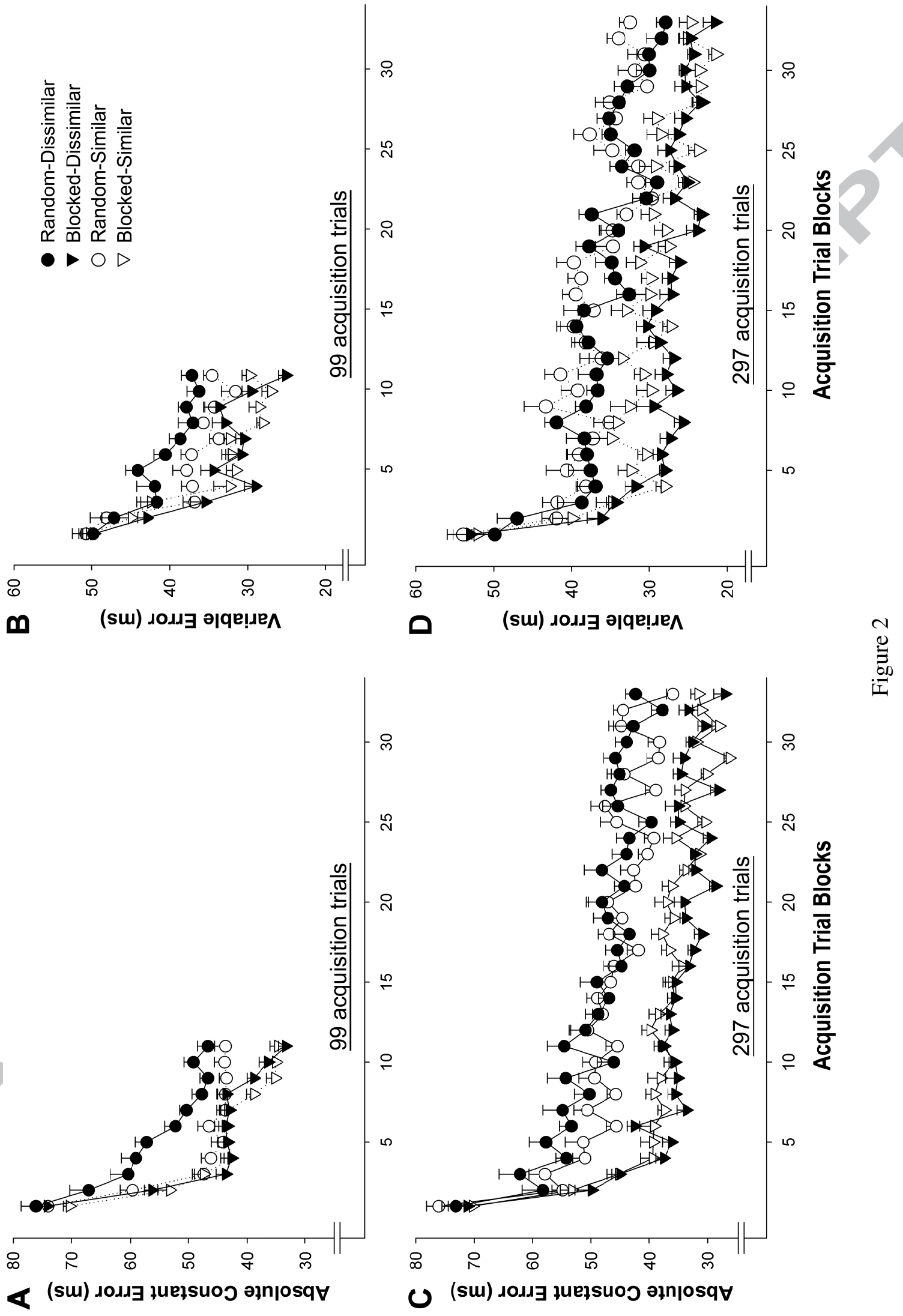


- Random-Dissimilar

V Blocked-Dissimilar

$\bigcirc$ Random-Similar

$\nabla$ Blocked-Similar
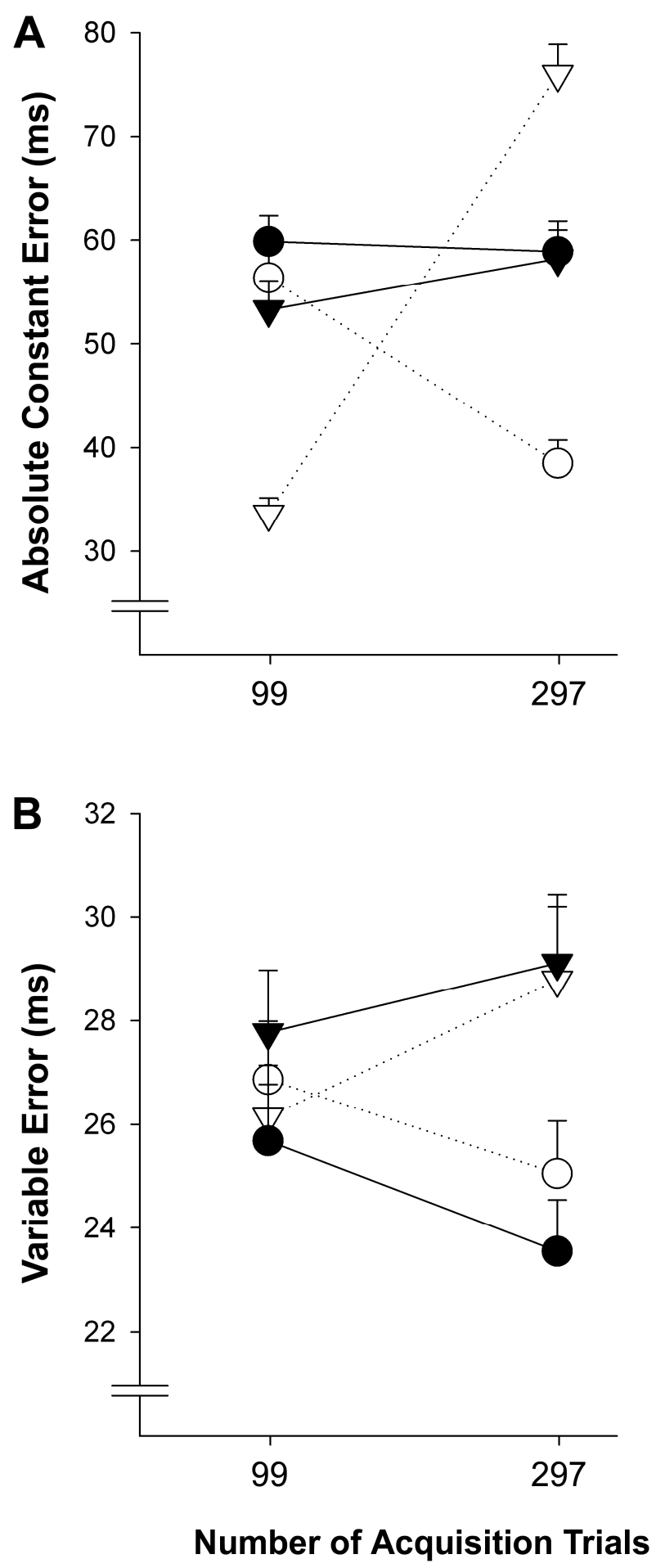

Figure 3 